\title{
CARACTERIZAÇÃO GEOMORFOLÓGICA DA BACIA HIDROGRÁFICA DO RIO DA SALSA, PARAÍBA-BRASIL
}

\author{
characterization geomorphologic of Salsa's River watershed, Paraiba-Brazil
}

Maria Emanuella Firmino Barbosa*

Max Furrier**

\begin{abstract}
Resumo
O presente trabalho almeja ampliar os conhecimentos sobre a geomorfologia da bacia hidrográfica do rio da Salsa, localizada no município do Conde, estado da Paraíba/Brasil. A pesquisa teve com objeto norteador elaborar cartas temáticas relacionadas aos aspectos morfométricos da bacia tais como: hierarquia fluvial, hipsometria e declividade e a realização de cálculos morfométricos, visando caracterizar, com maior detalhe, a geomorfologia da bacia hidrográfica. Após a obtenção dos dados morfométricos e da confecção dos produtos cartográficos pode-se avaliar prováveis influências da tectônica sobre a morfologia dessa bacia. Já de posse dos primeiros resultados observou-se o elevado nível de dissecação da Formação Barreiras e a discrepância dessa dissecação entre os divisores topográficos localizados ao leste e oeste da bacia hidrográfica do rio da Salsa. Na Formação Barreiras, foi possível observar indicativos de tectonismo a partir de recuos de cabeceiras com entalhes acentuados e bastante diferenciados entre os setores L e W, da direção subsequente do rio da Salsa S-N, que é discordante da direção dos principais cursos fluviais e da inclinação da própria Formação Barreiras que é de W-E, e de seu curso bastante retilíneo indicando um ajuste a uma linha de falha.
\end{abstract}

Palavras-chave: Bacia hidrográfica, Rio da Salsa, Formação Barreiras, Morfometria.

\begin{abstract}
The present work aims to extend knowledge about the geomorphology of Salsa's river watershed, located in the municipal district of Conde, State of Paraíba/Brazil. The research object was to develop thematic maps related to morphometric aspects of the basin how: fluvial hierarchy, hypsometric and slope. After obtaining the morphometric data can assess the likely tectonic influences on the morphology of the basin. Moreover, were made two topographical profiles of the area, through which it was possible to examine more detail the aspects geomorphological and Slope of basin. Already of possession of the first results of this study was observed with the analysis of charts and topographical profiles the high level of dissection of the Barreiras Formation and the dissection of this discrepancy between the margin left and right of Salsa's river. In the Barreiras Formation, it was observed indicative of tectonic retreats from the headwater notched quite different and the direction of the obsequent Salsa's river $(\mathrm{S}-\mathrm{N})$, which is discordant with the direction of main rivers and the inclination of the Barreiras Formation which is itself W-E and its fairly straight course indicating an adjustment to a fault line.
\end{abstract}

Key words: Watershed, Salsa river, Barreiras Formation, Morphometry.

\begin{abstract}
Resumen
El presente trabajo tiene como objetivo ampliar los conocimientos sobre la geomorfología de la cuenca del río de la Salsa, ubicado en el municipio de Conde, en el estado de Paraíba/Brasil. La investigación fue objeto de guiar y producir mapas temáticos relacionados con aspectos morfométricos de la cuenca, tales como: la jerarquía fluvial, hipsometria y la inclinación y el logro de los cálculos morfométricos para caracterizar, con mayor detalle, la geomorfología de la cuenca. Después de obtener los datos morfométricos y la confección de productos cartográficos puede evaluar posibles influencias tectónicas en la morfología de la cuenca del río. Ya en posesión de los primeros resultados observados el alto nivel de la disección de la Formación Barreiras, y la discrepancia de la disección entre los divisores topográficas situadas al este y al oeste de la cuenca del río de la Salsa. Na Formación Barreiras fue posible observar indicativo de tectónica en los reveses de cabecera con muescas acentuados y muy distinta entre los sectores L y W, la dirección subsequente del río de la Salsa S-N, lo que es incompatible con la dirección de los principales cursos de los ríos y la inclinación de propia Formación Barreiras que es W-E, y por supuesto, es bastante rectilínea que indica un ajuste a una línea de falla.
\end{abstract}

Palabras clave: Cuenca hidrográfica, Río de la Salsa, Formación Barreiras, Morfometría.

(*) Mestranda do Programa de Pós-Graduação em Geografia da Universidade Federal da Paraíba - Campus I, Departamento de Geociências. Cidade Universitária, Castelo Branco III CEP: 58059-900 - João Pessoa (PB), Brasil. Tel: (+ 5583$) 32167432$ - mariaemanuellaf@gmail.com

(**) Prof. Dr do Programa de Pós-Graduação em Geografia da Universidade Federal da Paraíba - Campus I, Departamento de Geociências. Cidade Universitária, Castelo Branco III CEP: 58059-900 - João Pessoa (PB), Brasil. Tel: (+ 5583$) 32167432$ - max.furrier@hotmail.com 


\section{INTRODUÇÃO}

O estudo foi realizado na bacia hidrográfica do rio da Salsa, localizada no município do Conde, estado da Paraíba/Brasil. Essa bacia está localizada nos Tabuleiros Litorâneos esculpidos sobre os sedimentos areno-argilosos mal consolidados da Formação Barreiras de idade atribuída ao Mioceno (ARAI, 2005).

A análise do relevo é de grande importância não só para a própria geomorfologia, mas também para as outras ciências da terra que estudam os componentes da superfície terrestre, bem como na definição de fragilidade/vulnerabilidade do meio ambiente e no estabelecimento de legislação para a sua ocupação e proteção. Dependendo de suas características, o relevo favorece ou dificulta a ocupação dos ambientes terrestres pelo homem, além disso, a geomorfologia dispõe de uma grande variedade de métodos, técnicas e equipamentos que permitem estudar com profundidade formas de relevo e processos geomorfológicos, ao combinar modelos de previsão, observações de campo e informações extraídas através de técnicas de Sistemas de Informações Geográficas (SIG) (FLORENZANO, 2008).

A pesquisa teve com objeto norteador a elaboração de cartas temáticas relacionadas aos aspectos morfométricos da bacia tais como: hierarquia fluvial, hipsometria e declividade. Foram realizados cálculos morfométricos seguindo a metodologia de Strahler (1957). Visando quantificar as principais características morfológicas, produzindo cartas temáticas que visam compreender a evolução geomorfológica da bacia. Os produtos cartográficos gerados bem como os resultados morfométricos obtidos poderão auxiliar futuras intervenções antrópicas na mesma.

A bacia do rio da Salsa é composta pelo rio principal denominado rio da Salsa, pelo riacho da Bica e demais córregos sem denominação. A bacia está localizada entre as coordenadas de longitude $34^{\circ} 55^{\prime} 12,91^{\prime \prime} / 34^{\circ} 50^{\prime} 51,07^{\prime \prime} \mathrm{W}$ e latitude $7^{\circ} 18^{\prime} 21,47^{\prime \prime} / 7^{\circ} 14^{\prime} 0,01^{\prime \prime} \mathrm{S}$.

A partir desse estudo almeja-se contribuir para um melhor conhecimento da dinâmica dos processos geomorfológicos na área em questão enfatizando, também, os outros componentes da paisagem e suas interrelações, fornecendo assim dados que possam servir de subsídio para projetos de planejamento ambiental e territorial.

\section{METODOLOGIA}

Os materiais utilizados foram: cartas topográficas do Conde (SB.25-Y-C-III-3-NO), Jacumã (SB.25- Y-C-III-3-NE), Santa Rita (SB.25-Y-C-III-1-SO) e Nossa Senhora da Penha (SB.25-Y-CIII-1-SE), todas na escala de 1: 25.000 (SUDENE, 1974), com equidistância entre as curvas de nível de $10 \mathrm{~m}$. Foi feito um mosaico da bacia com as cartas topográficas e em seguida a imagem foi importada para o Software Spring 5.1.7, para ser realizado o processo de vetorização. Concluído o processo de vetorização, foi elaborado o Modelo Numérico do Terreno (MNT) da bacia e com esses dados pode-se fazer o processo de contagem e mensuração dos canais e, por fim, a confecção das cartas temáticas.

Foram confeccionadas as cartas hipsométrica e clinográfica. Na carta hipsométrica foram delimitadas as altimetrias de 0 - $10 \mathrm{~m}$, para se detalhar com maior precisão as planícies e terraços fluviais, e a partir dos $10 \mathrm{~m}$ foram delimitadas altimetrias com intervalo de $20 \mathrm{~m}$ até o patamar de $140 \mathrm{~m}$. Na carta clinográfica foram adotadas as classes de declividade proposta por Herz e De Biasi (1989) que amarram essas classes aos limites utilizados internacionalmente, bem como a trabalhos desenvolvidos por institutos de pesquisa nacionais e a leis vigentes no Brasil.

As classes de declividades elaboradas por Herz e De Biasi (1989) foram delimitadas e especificadas da seguinte forma:

- $<12 \%$ - Faixa que define o limite máximo para o emprego de mecanização agrícola (CHIA-

RINI; DONZELLI, 1973 apud, HERZ; DE BIASI, 1989); 
- 12-30\% - Lei Federal 6.766/79 limita em 30\% de declividade a urbanização sem restrições;

- 30-47\% - Lei Federal 4.771/65 (Código Florestal) limita em 47\% de declividade o corte raso da vegetação;

- 47-100\% - Lei Federal 4.771/65 (Código Florestal) proíbe a derrubada de floresta neste intervalo de declividade sem um regime de utilização racional que vise a rendimentos permanentes;

- 100\% - Lei Federal 4.771/65 (Código Florestal) considera toda a área com esta declividade e superior como área de preservação permanente.

Os cálculos referentes aos aspectos morfométricos foram: relação de bifurcação $(\mathrm{Rb})$, comprimento dos canais de cada ordem $(\mathrm{L})$, comprimento médio dos seguimentos $(\mathrm{Lm})$, relação entre o índice do comprimento médio dos canais e o índice de bifurcação (Rib), relação entre os comprimentos médios dos canais (RLm) e o comprimento do rio principal. Com os resultados dos cálculos morfométricos e das cartas temáticas geradas pode-se fazer um diagnóstico detalhado da bacia quanto ao grau de dissecação, discrepância de canais entre os setores $\mathrm{L}$ e W, evidências de tectônica recente através dos desníveis altimétricos verificados e do ajuste estrutural da bacia.

\section{RESULTADOS}

Com a análise das cartas temáticas constatou-se a elevada dissecação da Formação Barreiras e a diferença dessa dissecação entre os setores $\mathrm{W}$ e L da bacia hidrográfica (Figura 1). Na Formação Barreiras, foi possível observar indicativos de tectonismo a partir da discrepância entre os entalhes fluviais e recuos de cabeceiras entre os dois setores da bacia. Isto se torna importante, pois a análise morfológica desta unidade litoestatigráfica é de suma importância para a compreensão dos mecanismos que regem a geomorfologia do litoral nordestino, principalmente, no tocante aos mecanismos que regem as morfologias das bacias hidrográficas do litoral da Paraíba, muitas delas fortemente atreladas ao fator tectônico.

A bacia do rio da Salsa possui uma área de aproximadamente $23,6 \mathrm{~km}^{2}$ tendo seu escoamento superficial perpendicular, no sentido $\mathrm{S}-\mathrm{N}$, à inclinação das camadas sedimentares que se encontram dispostas de W-L. O rio principal possui um padrão retilíneo, corroborando a hipótese que o seu curso está disposto sobre uma linha de falha com rejeito vertical, sendo evidenciada pelo desnível altimétrico acentuado entre os setores W e L da bacia. Para Howard (1967) uma anomalia de drenagem pode ser compreendida como uma discordância local da drenagem regional e/ou dos padrões de canais, sugerindo desvios topográficos ou estruturais. Uma das anomalias identificadas na bacia em estudo foram: o padrão retilíneo do curso principal e anômalo em relação ao padrão de drenagem regional.

Observando a carta hipsométrica da bacia do rio da Salsa (Figura 1), nota-se que o setor oeste da bacia tem uma maior elevação quando comparado ao setor leste, chegando a patamares que atingem 121 metros de altitude. Comparando-se com o setor leste, os patamares são mais rebaixados, alcançando a altitude máxima de 92 metros, perfazendo um desnível entre os dois setores de 29 metros. Outro ponto relevante constatado e bastante visível na carta hipsométrica e na carta clinográfica (Figuras 1 e 2) é a acentuada dissecação do relevo no setor oeste da bacia originando amplos anfiteatros erosivos e com maior número de afluentes.

Na carta clinográfica (Figura 2) observa-se que as maiores declividades estão nas cabeceiras de drenagem da porção oeste da bacia do rio da Salsa. Avaliando toda a área de estudo chega-se ao resultado de que uma considerável parte da bacia possui declividades em torno de 0 - $12 \%$ que corresponde aos topos aplainados dos tabuleiros e as planícies e terraços fluviais. Há também o predomínio das declividades entre 12-30\% nas cabeceiras de drenagem, porém na porção NW, 


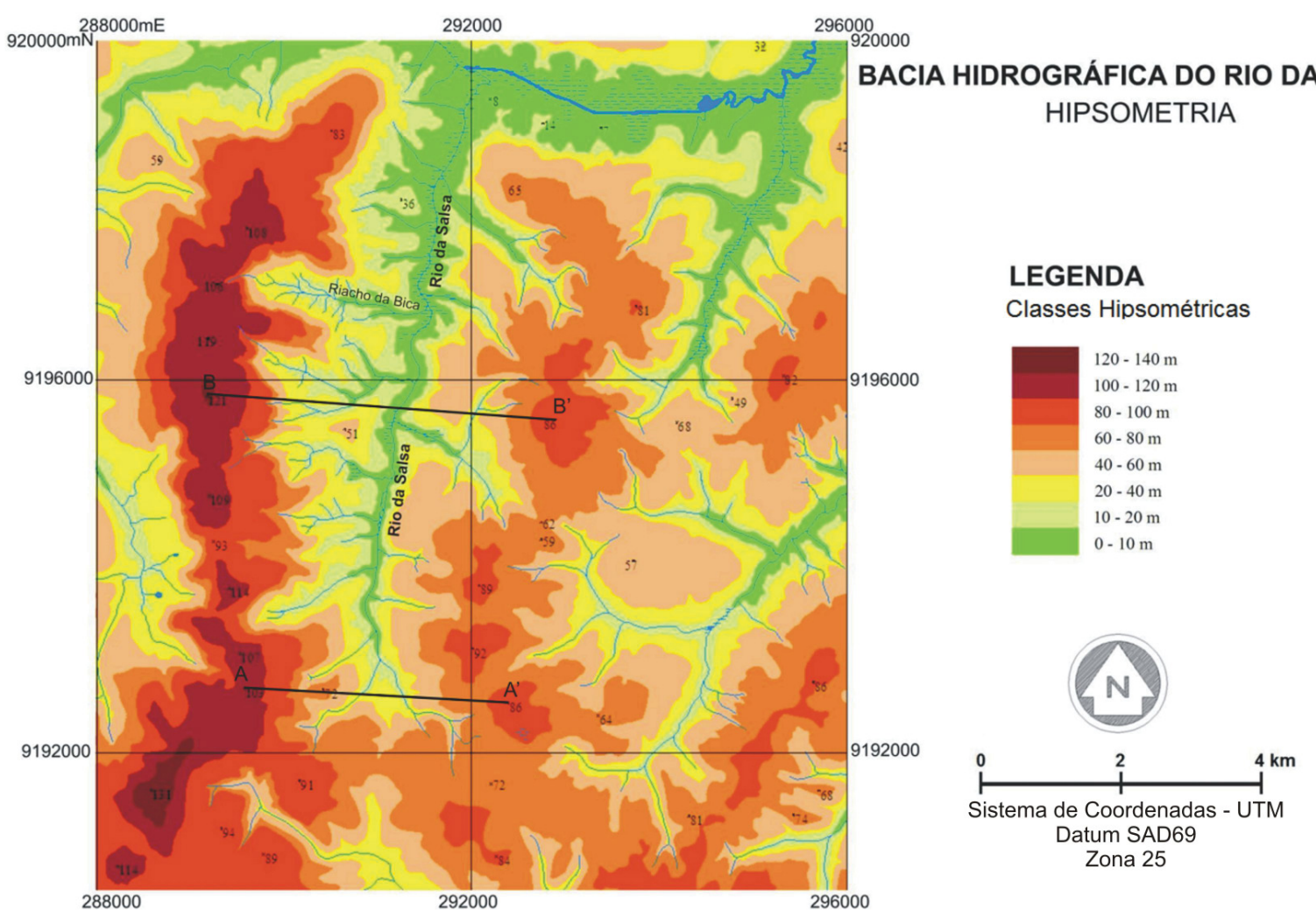

Figura 1 - Carta hipsométrica da bacia hidrográfica do rio da Salsa e adjacências. Observar que as maiores altitudes estão na porção oeste da bacia.

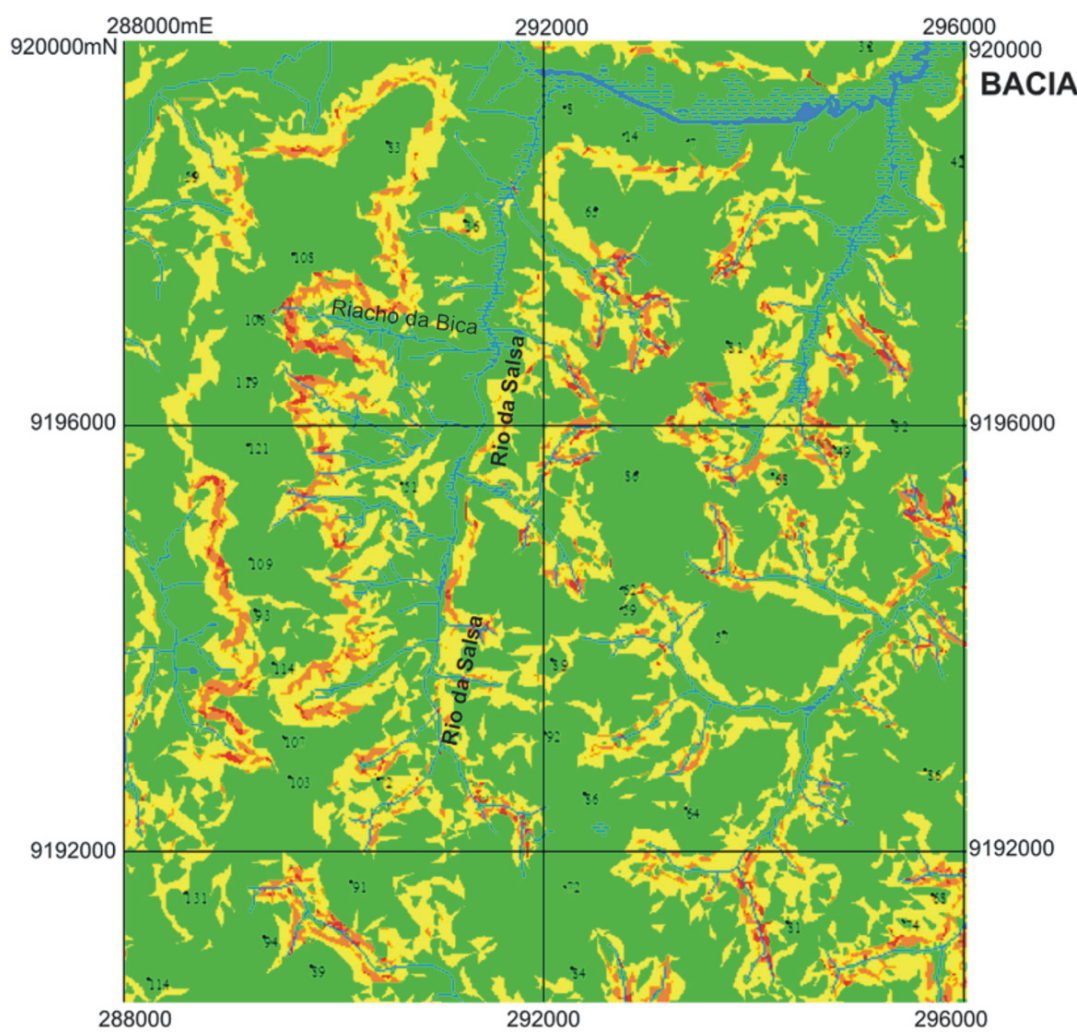

\section{BACIA HIDROGRÁFICA DO RIO DA SALSA} DECLIVIDADE

LEGENDA

classes de declividade

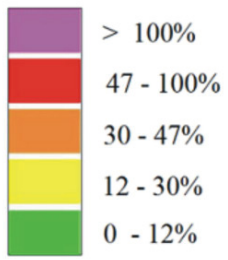

Figura 2 - Carta clinográfica da bacia hidrográfica do rio da Salsa e adjacências. 
correspondente ao riacho da Bica e seus afluentes, pode-se encontrar valores de 47-100\%. Na porção NE verificam-se, também, valores entre 47-100\%, embora esta fração da área possua altitudes inferiores ao setor $\mathrm{W}$, o que pode corroborar com a evidência de um pulso de soerguimento nesta porção. Outra dado que corrobora a evidência de influência de tectonismo recente é a morfologia da cabeceira de drenagem que se encontra bastante entalhada com declividades elevadas que atestam um recuo acelerado.

\section{HIERARQUIA FLUVIAL E CÁLCULOS MORFOMÉTRICOS}

A hierarquia de uma bacia hidrográfica consiste no processo de estabelecer a classificação de determinado curso de água (ou da área drenada que lhe pertence) no conjunto total da bacia hidrográfica na qual se encontra (STRAHLER, 1957). Para a extração do comprimento dos canais de cada ordem deve ser levada em consideração a lei do número de canais, onde, não se considera nenhuma mensuração, mas somente o ponto de origem e a confluência dos seguimentos (HORTON, 1945). Ela pode ser aplicada com a mesma exatidão nas bacias hierarquizadas conforme o sistema de Horton ou com o de Strahler (CHRISTOFOLETTI, 1980). Isso é realizado com a função de facilitar e tornar mais objetivo os estudos morfométricos sobre as bacias hidrográficas (Figura 3).

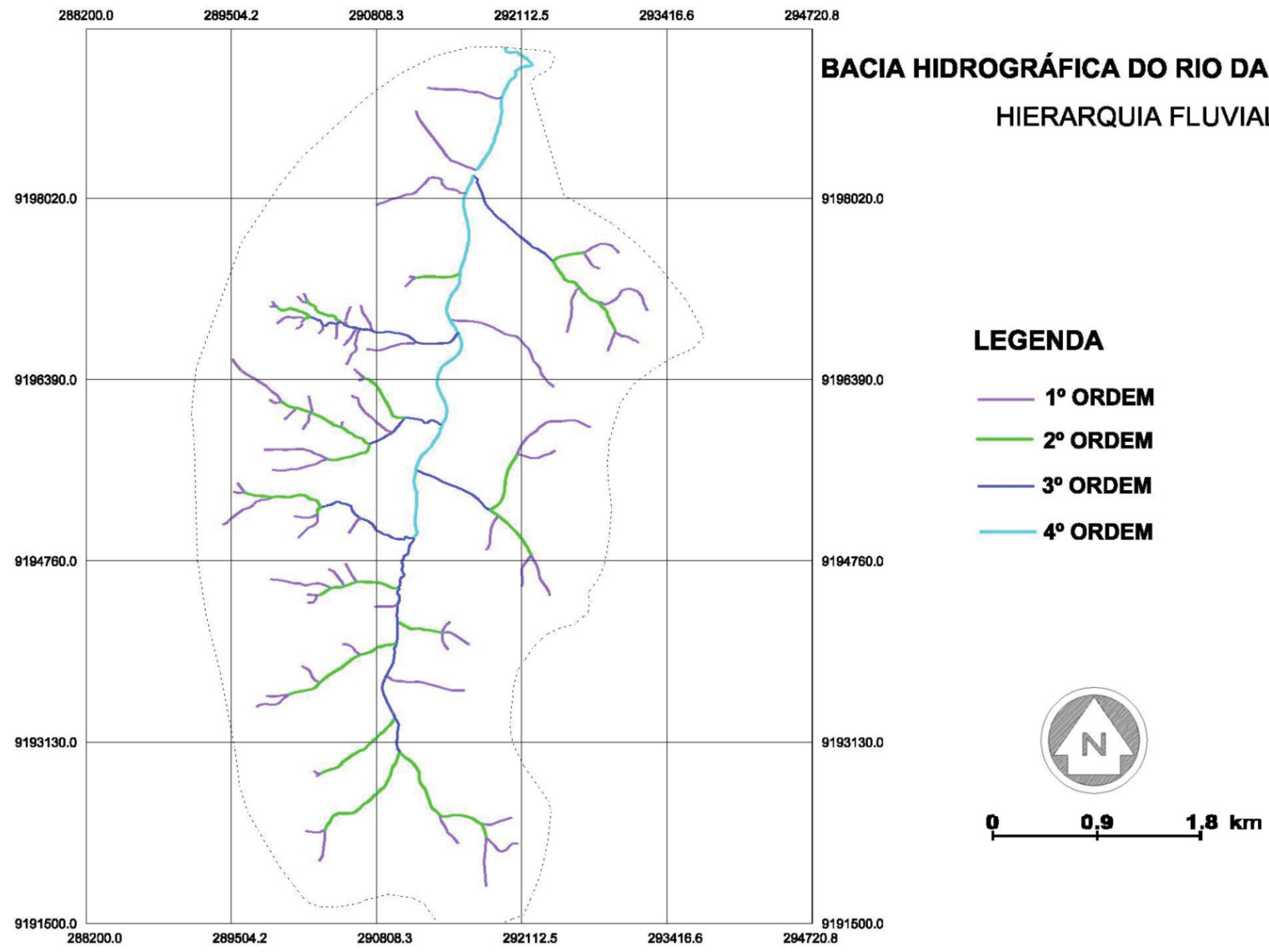

Figura 3 - Hierarquia fluvial da bacia hidrográfica do rio da Salsa.

A partir dos dados obtidos com a hierarquização se chegou ao resultado que a bacia hidrográfica do rio da Salsa é de $4^{\text {a }}$ ordem, possuindo ao todo 94 canais, que estão distribuídos segundo as suas ordens hierárquicas na tabela abaixo (Tabela 1). Outro ponto constatado através da hierarquia fluvial é a diferença conspícua no número de caudais entre os setores $\mathrm{W}$ e $\mathrm{L}$ e o desenvolvimento dos mesmos, visto o setor $\mathrm{W}$ apresenta mais caudais de $2^{\mathrm{a}}$ e $3^{\mathrm{a}}$ ordens que o setor L. 
Tabela 1 - Resultados da morfometria da bacia hidrográfica do rio da Salsa

\begin{tabular}{|c|c|c|c|c|c|c|}
\hline Ordem & $\begin{array}{l}\text { № de } \\
\text { Canais }\end{array}$ & $\begin{array}{l}\text { Relação de } \\
\text { bifurcação }\end{array}$ & $\begin{array}{l}\text { Comprimento dos } \\
\text { canais de cada } \\
\text { ordem (L) }\end{array}$ & $\begin{array}{l}\text { Comprimento médio dos } \\
\text { seguimentos }(\mathrm{Lm})\end{array}$ & $\begin{array}{l}\text { Relação entre os } \\
\text { comprimentos } \\
\text { médios dos canais } \\
\text { (RL m) }\end{array}$ & $\begin{array}{c}\text { Relação entre o índice do } \\
\text { comprimento médio dos } \\
\text { canais e o índice de bifur- } \\
\text { cação (Rib) }\end{array}$ \\
\hline \multirow[t]{2}{*}{$1 \underline{a}$} & 69 & & 21,324 & 0,309 & & \\
\hline & & 3,83 & & & 1,951 & 0,513 \\
\hline \multirow[t]{2}{*}{$2^{\mathrm{a}}$} & 18 & & 10,849 & 0,603 & & \\
\hline & & 3 & & & 1,492 & 0,498 \\
\hline \multirow[t]{2}{*}{3 a } & 6 & & 5,402 & 0,9 & & \\
\hline & & 6 & & & 5,441 & 0,907 \\
\hline 4a & 1 & & 4,897 & 4,897 & & \\
\hline
\end{tabular}

Os aspectos morfométricos das bacias hidrográficas refletem algumas das interrelações mais significativas entre os principais fatores responsáveis pela evolução e organização do modelado, em particular a geomorfologia. Os cálculos morfométricos relacionados a caracteres espaciais, lineares e hipsométricos da drenagem contribuem para uma melhor caracterização das unidades geomorfológicas, cuja qualidade e precisão variam conforme a particularidade redacional do pesquisador.

Pode-se ressaltar a importância quantitativa que a aplicação dos cálculos morfométricos dá à pesquisa, possibilitando a comparação concreta com resultados obtidos em estudos efetuados em outras bacias hidrográficas situadas na região, ou até mesmo em bacias localizadas em regiões díspares, mas que estejam localizadas sobre a mesma formação litológica e com contexto climático semelhante. Outro fator que ressalta a importância da morfometria em estudos de bacias hidrográficas é a utilização dos resultados alcançados em projetos de engenharia, bem como em qualquer outro tipo de intervenção antrópica onde há a necessidade de dados quantitativos pretéritos.

Analisando os resultados do índice da Relação de bifurcação constatou-se que todos os resultados foram superiores a dois $(\mathrm{Rb} \geq 2)$, como estabelecido por Strahler (1957) (Tabela I). Segundo Silva et al. (2003), o valor desse parâmetro é maior para áreas amorreadas, com bacias de drenagem muito dissecadas, do que para bacias com áreas colinosas, sendo de 3 a 4 para as primeiras e mais próximo de 2 para as últimas. Esse valor encontrado não é comum para bacias situadas em áreas de geologia sedimentar e formas tabulares como a bacia em questão, o que pode evidenciar a atuação da tectônica na área.

Porém, Christofoletti (1969) menciona que Strahler (1952), observa a não validade dessa regra de relação, sugerindo ser mais consistente a regra que associa o substrato geológico com o grau de permeabilidade e da resistência erosiva desse substrato à relação de bifurcação. Nesse caso o valor obtido estaria mais próximo aos valores encontrados para bacias hidrográficas localizadas em áreas com substrato cristalino e não em áreas com substrato sedimentar como a bacia em questão, onde o ideal seria valores da Relação de bifurcação menores que $2(\mathrm{Rb}<2)$.

A relação entre o índice do comprimento médio dos canais e o índice de bifurcação (Rib) é um importante elemento na relação entre a composição da drenagem e o desenvolvimento morfológico das bacias hidrográficas. Se a relação entre o comprimento médio e o índice de bifurcação for igual, o tamanho médio dos canais crescerá ou diminuirá na mesma proporção. Caso não sejam iguais, o que é mais comum, o tamanho dos canais poderá diminuir ou aumentar progressivamente com a elevação da ordem dos canais, pois são os fatores hidrológicos, morfológicos e geológicos que determinam o último grau do desenvolvimento da drenagem em determinada bacia (CHRISTOFOLETTI, 1980). Os valores obtidos para a bacia do rio da Salsa entre o comprimento médio dos canais e o índice de bifurcação são diferentes, corroborando a hipótese de influência tectônica na área visto que a bacia percorre somente uma litologia (Formação Barreiras), que sustenta apenas um compar- 
timento morfológico (Tabuleiros Litorâneos), que está inserido em apenas um domínio climático (tropical úmido) e possui uma dimensão areal pequena $(23,6 \mathrm{~km} 2)$. A configuração morfológica da área atrelada ao fator tectônico já foi discutida em trabalhos de Bezerra et al. (2001), Furrier et al. (2006), Furrier (2007) e Brito Neves et al. (2009), mas sem a utilização de dados morfométricos.

\section{CONSIDERAÇÕES FINAIS}

A configuração morfológica da bacia hidrográfica do rio da Salsa está intimamente atrelada ao fator tectônico recente, visto que toda área está assentada sobre a mesma litologia, a Formação Barreiras, constituída principalmente por sedimentos areno-argilosos mal consolidados. A discrepância altimétrica, os diferentes índices de declividade e a quantidade discrepante de canais fluviais dos setores leste e oeste, os amplos anfiteatros erosivos na porção oeste, o sentido subsequente (S-N) do rio principal corrobora fortemente para a aferição do fator tectônico como principal elemento na configuração morfológica da bacia.

Essas características são fortes evidências que o fator tectônico foi o grande influenciador na atual configuração do relevo da área e, consequentemente, dos padrões da rede de drenagem, já que a bacia apresenta uma área reduzida, não havendo diferenciação pluviométrica significante que poderia influenciar a morfologia da área ao ponto de produzir formas e arranjos tão distintos.

O conhecimento geomorfológico da bacia hidrográfica do rio da Salsa e o entendimento de seu comportamento morfológico e morfométrico poderão subsidiar inúmeras intervenções antrópicas que por ventura venham a ocorrer nessa bacia como: loteamentos, cultivos diversos, barragens, sendo esta última propícia na referida bacia devida sua morfologia alongada e com canais fortemente entalhados o que possibilitaria um armazenamento de água substancial com uma área alagada de proporções reduzidas.

Os produtos cartográficos confeccionados neste trabalho serão de fundamental importância no planejamento territorial e ambiental da área em questão, bem como servirão de ferramentas na implementação das prováveis intervenções acima descritas.

\section{REFERÊNCIAS BIBLIOGRÁFICAS}

ARAI, M. A grande elevação eustática do Mioceno: a verdadeira origem do Grupo Barreiras. In: CONGRESSO DA ASSOCIAÇÃO BRASILEIRA DE ESTUDOS DO QUATERNÁRIO, 10., 2005. Guarapari. Anais...Guarapari: ABEQUA, 2005.

BRITO NEVES, B. B.; ALBUQUERQUE, J. P. T.; COUTINHO, J. M. V; BEZERRA, F. H. R. Novos dados geológicos e geofísicos para a caracterização geométrica e estratigráfica da Sub-bacia Alhandra (Sudeste da Paraíba). Geologia USP: Série Científica, v. 9, n. 2, p. 63-87, 2009.

BEZERRA, F. H. R.; AMARO, F. R.; VITA-FINZI, C.; SAADI, A. Pliocene-Quaternary control of sedimentation and coastal plain morphology in NE Brazil. Journal of South American Earth-Science. V. 14, n. 1, p. 61-75, 2001.

CHRISTOFOLETT, A. Análise morfométrica de bacias hidrográficas. Notícia Geomorfológica, v. 18, n. 9, p. 35-64, 1969.

CHRISTOFOLETT, A. Geomorfologia. São Paulo: Edgard Blücher/EDUSP, 1980. 150p.

FORENZANO, T. G. Geomorfologia, conceitos e técnicas atuais. São Paulo: Oficina de Textos, 2008. 317 p.

FURRIER, M.; ARAÚJO, M. E.; MENESES, L. F. Geomorfologia e tectônica da Formação Barreiras no Estado da Paraíba. Geologia USP: Série Científica, v. 6, n. 2, p. 61-70, 2006.

FURRIER, M. Caracterização geomorfológica e do meio físico da Folha João Pessoa - 1: 100.000. 2007. 213f. Tese (Doutorado em Ciências) - Faculdade de Filosofia, Letras e Ciências Humanas, Universidade de São Paulo, São Paulo, 2007.

HERZ, F.; DE BIASE, M. Critérios e Legendas para Macrozoneamento costeiro. Brasília: Comissão 
Interministerial para os Recursos do Mar, 1989.

HORTON, R.E. Erosional development of streams and their drainage basins: hydrophysical aproach to quantitative morphology. Bulletin of the Geological Society of America, Washington, v.56, n.1, p.275-370, 1945. HOWARD, A. D. Drainage analysis in geologic interpretation: a summation. American Association of Petroleum Geology Bulletim, Tulsa, v. 51, n. 11, p 2246-2259, 1967.

SILVA, A. M.; SCHULZ, H. E. CAMARGO, P. B. Erosão e hidrossedimentologia em bacias hidrográficas. São Carlos: Rima, 2003. 140p.

SILVA, T. M. da; MONTEIRO, H. da S.; CRUZ, M. A.; MOURA, J. R. da S. de. Anomalias de drenagem e evolução da paisagem no médio vale do rio Paraíba do Sul (RJ/SP). Anuário do Instituto de Geociências. [online]. v. 29, n.2, p. 210-224, 2006.

STRAHLER, A. Quantitative analysis os watershed Geomorfology. American Geophysical Unon Transactions. v. 38, n. 6, p. 913-920, 1957.

SUDENE - SUPERINTENDÊNCIA DE DESENVOLVIMENTO DO NORDESTE. Folhas Conde, Jacumã, Santa Rita e Nossa Senhora da Penha. Recife: SUDENE, 1974. Escala 1:25.000.

Trabalho enviado em setembro de 2012

Trabalho aceito em novembro de 2012 